\title{
Atypical Progressive Multifocal Leukoencephalopathy in a Patient with Antisynthetase Syndrome
}

\author{
Moncef Belhassen-Garcia ${ }^{1}$, Alberto Rábano-Gutiérrez ${ }^{2}$, Virginia Velasco-Tirado ${ }^{1}$, \\ Angela Romero-Alegria ${ }^{3}$, Maria-Luisa Pérez-Garcia ${ }^{3}$ and Jose Angel Martin-Oterino ${ }^{3}$
}

\begin{abstract}
Antisynthetase syndrome is a disorder belonging to the dermatomyositis/polymyositis group, with high rates of morbidity and mortality. We herein present the case of a 71-year-old man who was diagnosed with antisynthetase syndrome and treated with rituximab. Almost three years later, the patient showed right-sided hemiparesis that ultimately progressed to complete hemiplegia and advancing cognitive deterioration with a poor clinical outcome. The neuropathological diagnosis was progressive multifocal leukoencephalopathy. Treatment with rituximab for antisynthetase syndrome itself plays a fundamental role in the development of infectious complications.
\end{abstract}

Key words: Anti-Jo-1, antisynthetase syndrome, rituximab, progressive multifocal leukoencephalopathy, JC virus

(Intern Med 54: 519-524, 2015)

(DOI: 10.2169/internalmedicine.54.2748)

\section{Introduction}

Antisynthetase syndrome is included in the group of dermatomyositis disorders. It is a systemic inflammatory disease with high rates of both morbidity and mortality of infectious origin. Rituximab is a biological agent used to treat such patients and is well tolerated (1-5). Although rituximab therapy appears to increase the incidence of infectious complications $(6,7)$, there is a lack of sufficient long-term data regarding this point. Among infectious complications, progressive multifocal leukoencephalopathy (PML) is extremely rare in patients with dermatomyositis associated with rituximab treatment (8). PML presents as a series of classic symptoms with three atypical variants: i) cerebellar involvement, ii) encephalopathy or iii) inflammatory involvement. We herein present the case of a patient with antisynthetase syndrome who developed atypical PML after receiving rituximab.

\section{Case Report}

The patient was a 71-year-old man with a diagnosis of antisynthetase syndrome associated with fever, weakness of the hip and shoulder girdle, Raynaud's phenomenon, polyarthralgia and polyarthritis in both wrists, diffuse interstitial disease with cytogenic organizing pneumonia and autoimmunity presenting with extractable nuclear antigen (ENA) (Anti-Ro antibodies $233 \mathrm{U} / \mathrm{mL}$ ), antinuclear antibody (ANA) (1/640, speckled and cytoplasmic pattern) and anti-Jo-1 antibodies $445 \mathrm{U} / \mathrm{mL}$. We started treatment with methylprednisolone (1 $\mathrm{mg} / \mathrm{kg} / \mathrm{day})$ and azathioprine $(0.75 \mathrm{mg} / \mathrm{kg} / \mathrm{day})$, and the patient's symptoms subsided. However, six months after the diagnosis, he developed a fever and muscle weakness in both wrists (4/5). A laboratory analysis showed an aspartate aminotransferase (AST) level of $730 \mathrm{U} / \mathrm{L}$, alanine aminotransferase (ALT) level of $339 \mathrm{U} / \mathrm{L}$, creatine kinase (CK) level of 6,310 U/L, myoglobin level of 4,170 $\mu \mathrm{g} / \mathrm{L}$, lactate dehydrogenase (LDH) level of 1,190 U/L and ferritin level of $1,090 \mathrm{ng} / \mathrm{mL}$. A muscle biopsy revealed inflamma-

\footnotetext{
${ }^{1}$ Department of Internal Medicine, Unit of Infectious Diseases. IBSAL. University Hospital of Salamanca. CIETUS, University of Salamanca, Spain, ${ }^{2}$ Department of Neuropathology and Tissue Bank, Research Unit of Alzheimer Project. CIEN Foundation, ISCIII, Spain and ${ }^{3}$ Department of Internal Medicine, IBSAL. University Hospital of Salamanca, Spain

Received for publication February 21, 2014; Accepted for publication July 16, 2014

Correspondence to Dr. Moncef Belhassen-Garcia, mbelhassen@hotmail.com
} 

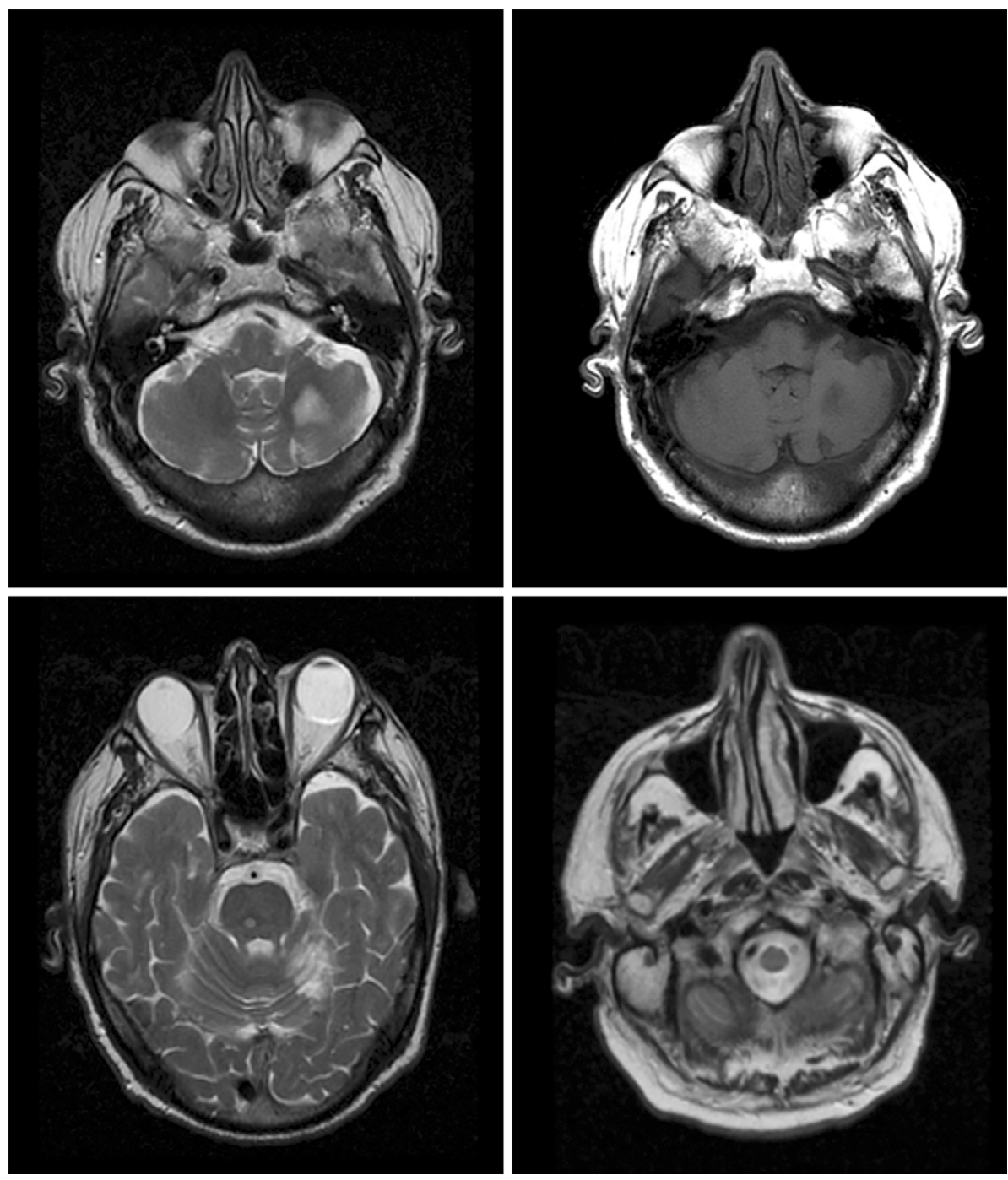

Figure 1. An image showing multiple intra-axial lesions with millimetric peripheral ring enhancement coexisting with poorly defined areas and irregular enhancement in the left cerebellar hemisphere.

tory myopathy compatible with polymyositis. Therefore, the dose of methylprednisolone was increased $(1 \mathrm{mg} / \mathrm{kg} /$ day $)$, and azathioprine $(2 \mathrm{mg} / \mathrm{kg} /$ day) was added to the treatment regimen. After six months without a response, therapy with rituximab was administered (375 $\mathrm{mg} / \mathrm{m}^{2} /$ week) for four weeks, with good symptom improvement. Nevertheless, nine months after the start of treatment with rituximab, the patient exhibited a new outbreak of myositis. The dose of methylprednisolone was again increased $(1 \mathrm{mg} / \mathrm{kg} / \mathrm{day})$, and mycophenolate mofetil was added (720 mg/12 hours), in addition to a second cycle of rituximab, which also resulted in a good response. Ten months after the beginning of the second cycle of rituximab, the patient presented with rightsided hemiparesis with brachial predominance and hyperreflexia as well as a right-sided extensor plantar cutaneous reflex. A cerebral CT scan revealed cortico-subcortical atrophy and a left cerebellar ischemic lesion. Cerebral MRI (Fig. 1, 2) showed multiple intra-axial lesions with millimetric peripheral ring enhancement coexisting with poorly defined areas with irregular enhancement in the left pre-
Rolandic area, right parieto-occipital region and left cerebellar hemisphere. Serology for herpes simplex virus, varicella zoster virus, cytomegalovirus, HIV, Toxoplasma gondii, Treponema pallidum and Borrelia burgdorferi was negative. The cerebrospinal fluid (CSF) displayed slight hyperproteinorrachia with a normal adenosine deaminase (ADA) titer. The results of flow cytometry and oligoclonal bands in the CSF were not pathologic. Cultures for bacteria, mycobacteria and fungi were negative, as was polymerase chain reaction (PCR) for Mycobacterium tuberculosis, cytomegalovirus, herpes virus and JC virus in the CSF.

During hospitalization, the patient progressed towards complete hemiplegia and with cognitive deterioration associated with episodes of psychomotor agitation and a decreased level of consciousness. He ultimately died after an episode of bronchoaspiration; a general autopsy revealed aspiration pneumonia as the cause of death. An examination of the brain did not show any relevant alterations in the cortical pattern, and the surface vessels contained minimal amounts of plaque of atheroma, without significant stenosis. Sections 

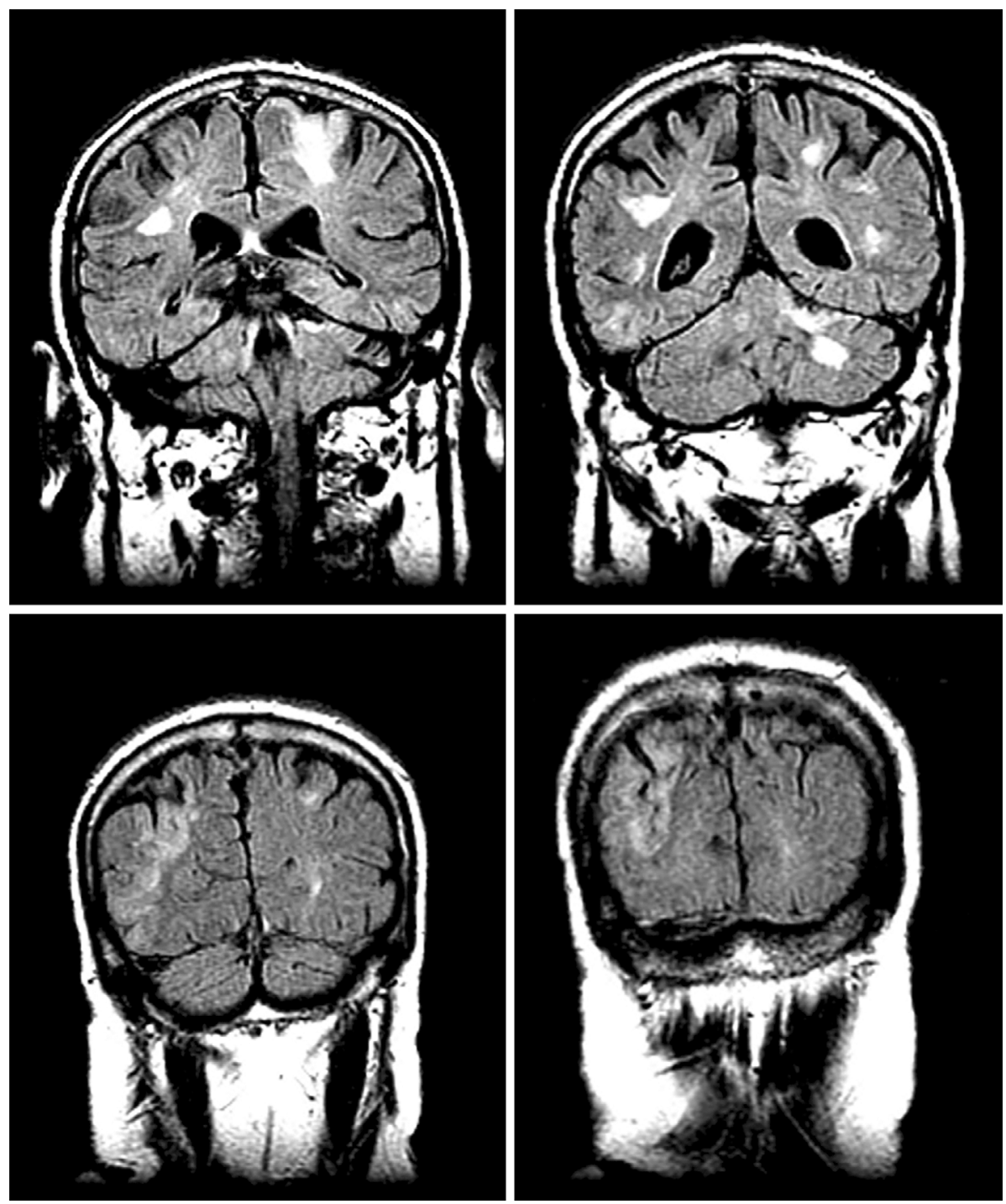

Figure 2. An image showing multiple intra-axial lesions with millimetric peripheral ring enhancement coexisting with poorly defined areas and irregular enhancement in the left pre-Rolandic and right parieto-occipital regions.

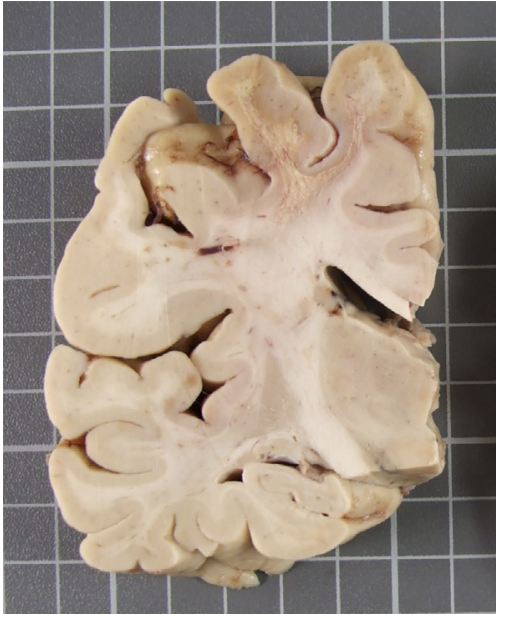

Figure 3. Focal lesions in the subcortical white matter of the peri-Rolandic region and parietal and occipital lobes with a yellowish area of retraction. of both brain hemispheres exhibited wide focal lesions in the left peri-Rolandic region and white subcortical matter of the right parietal and occipital lobes, with a yellowish area of retraction (Fig. 3). The lesions were connected to wide areas occupied by foamy histiocytes associated with a limited amount of interstitial and perivascular lymphocytic infiltrates (Fig. 4A). Images showed frequent cell elements compatible with oligodendrocytes containing amphophilic nuclei with a ground glass pattern (Fig. 4B) as well as giant astrocytes with irregular or multilobulated nuclei (Fig. 4C) immunoreactive for glial fibrillary acidic proteins (Fig. 4D). The lesions primarily affected the subcortical white matter and spread focally to the suprajacent cortex, with severe gliosis, frequent ballooning neurons and occasional giant astrocytes. Images also revealed millimetric and demyelinating subcortical lesions without foamy histiocytes in the frontal, parietal, lateral temporal and parahippocampal cortices. Meanwhile, the left cerebellar hemisphere exhibited cavitated lesions with an irregular edge along the surface meas- 

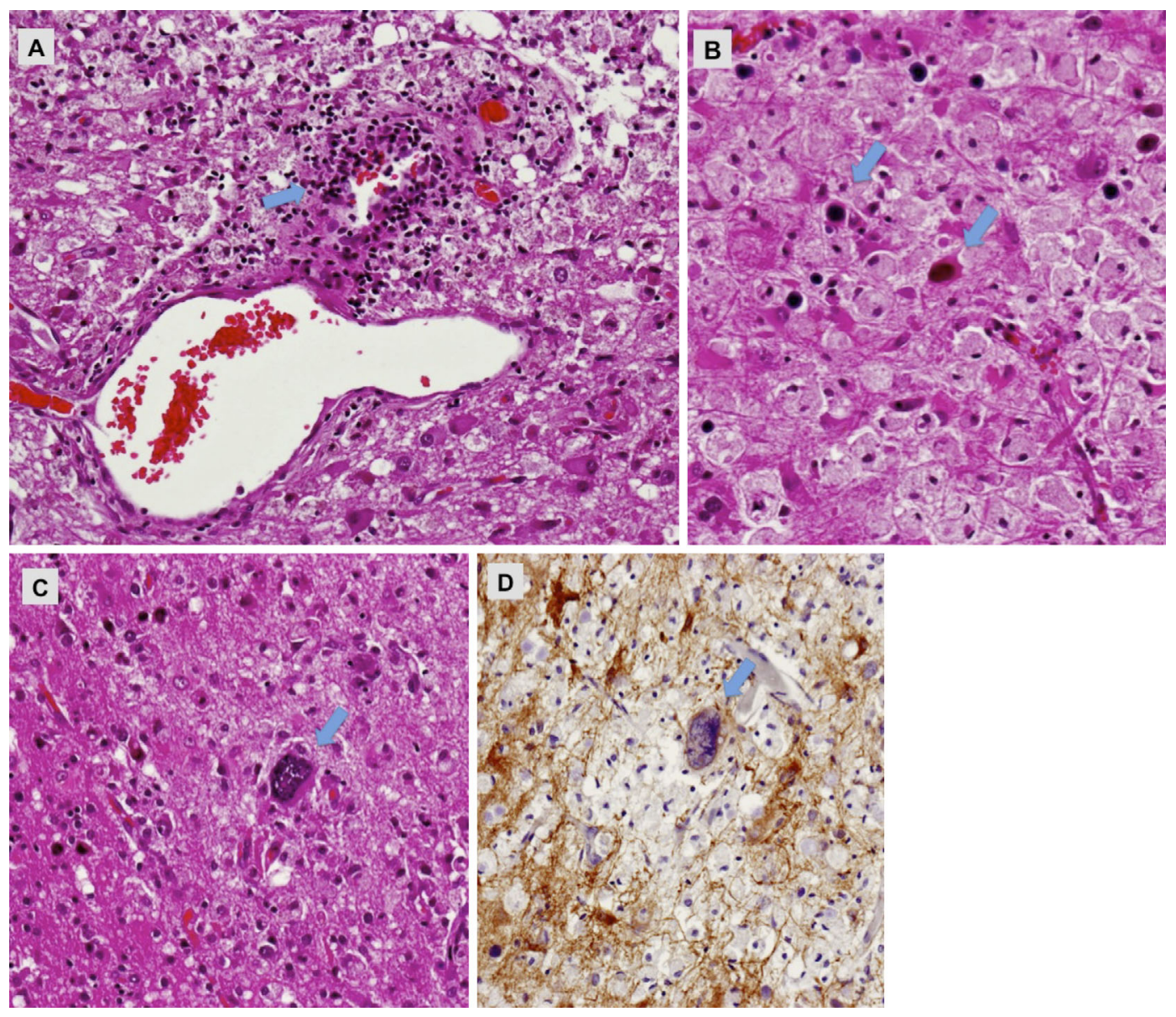

Figure 4. A: Wide lesions occupied by foamy histiocytes associated with limited interstitial and perivascular lymphocytic infiltrates. B: Cell elements compatible with oligodendrocytes exhibiting amphophilic nuclei and a ground glass pattern. C: Giant astrocytes with irregular or multilobulated nuclei. D: Astrocytes immunoreactive for glial fibrillary acidic proteins.

uring $4 \times 2 \mathrm{~cm}$ and a histological pattern similar to that seen in the white matter, with intense cortical atrophy. The neuropathological diagnosis was progressive multifocal leukoencephalopathy.

\section{Discussion}

Antisynthetase syndrome is classified as a form of dermatomyositis. Predisposing factors for opportunistic infections in the dermato/polymyositis group include thoracic myopathy, lymphopenia, esophageal involvement and treatment with cytotoxic drugs (8).

Among second-line drugs for antisynthetase syndrome, rituximab is used in refractory cases (1-5), although it may induce infectious complications $(6,7)$, with an incidence of severe infections of up to $9 \%$ in patients with autoimmune diseases (9). In a study of 279 patients with dermatomyositis and infection, there was a single case of PML associated with previous treatment with rituximab (8). Other cases of PML associated with other immunosuppressant therapies have also been described, although they are rare $(10,11)$.

PML is a severe disease caused by demyelinization of the central nervous system due to reactivation of the JC vi- rus (12). The JC virus is a small ubiquitous DNA neurotropic virus in the family of polyomaviridae (which includes other viruses such as KI, WU, Merkel and BK). The pathogenesis of KI and WU infection in humans is currently under discussion (13-15). The BK virus is primarily detected in patients with AIDS and has not been described in patients with autoimmune diseases (16). Meanwhile, the JC virus is commonly found in humans and remains latent in the kidneys, bone marrow and lymphoid tissue (12). Studies of the seroprevalence of the JC virus have demonstrated a prevalence of up to $86 \%$ in healthy populations (12). The JC virus damages oligodendrocytes and astrocytes, thus resulting in neurological deficits associated with areas of demyelination $(12,17)$.

The virus causes symptoms in patients with severe immunodeficiency (AIDS, autoimmune diseases and hematologic neoplasms) $(18,19)$. An analysis of 9,675 patients with PML revealed $0.44 \%$ of the cases to involve patients with systemic lupus erythematosus, $0.25 \%$ rheumatoid arthritis and $0.06 \%$ other connective tissue diseases (20). Rituximab is a biological drug reported to induce monoclonalassociated PML; however, its role in the development of PML is unclear. Although humoral control plays a secon- 
dary role in the latency of the JC virus, the loss of B cells is fundamental.

The present patient presented with a clinical form including combined elements of the inflammatory variant and cerebellar involvement, which has not previously been described in patients with autoimmune diseases.

The clinical symptoms are non-specific, including cephalalgia, apraxia, convulsions, hemianopsia, cognitive deficits, dementia, aphasia and sensorimotor deficits $(12,16)$. These symptoms develop over the course of weeks, as in the present case, leading to infradiagnosis.

The diagnosis is usually reached based on a combination of clinical, microbiology and radiology results. Cerebral biopsies (the gold standard procedure) are used only in complex cases, with a sensitivity ranging from 64 to $96 \%$ and specificity of $100 \%$ (21). The findings are similar for PCR of the CSF, with a sensitivity of $60-92 \%$ and a specificity of $92-100 \%$, although the results depend largely on the laboratory, degree of immunodepression and spectrum of infection (22-24). Therefore, in patients treated with immunodepressant drugs, a negative PCR finding does not rule out a diagnosis of PML, as in the current case (10).

The classic form of presentation of PML involves multiple symmetrical or asymmetrical lesions on cerebral MRI, without a vascular distribution, contrast enhancement or mass effect, affecting the white matter (12). However, our patient exhibited features compatible with non-classic PML on MRI, such as increased enhancement (which suggested edema and rupture of the brain-blood barrier) and cerebellar involvement (very rare radiological lesions) $(12,22)$. On the other hand, forms of polyomavirus other than the JC virus, such as the BK virus, may involve the cerebellum, which has a tendency to increase enhancement (16) and thus prompt us to consider the possibility that our patient's PML symptoms were caused by a polyomavirus other than the JC virus.

However, this discussion is merely academic, as there is no specific treatment, and the only possible line of action is to recover the patient's immunodepression. Although some cases of partial success have been described among patients treated with cidofovir (25), the mortality rate of those with PML after receiving rituximab is approximately $90 \%(12,26)$.

In conclusion, rituximab is a biological drug that may induce the development of monoclonal-associated PML. It is necessary to consider the possible role of polyomaviruses other than the JC virus in patients with antisynthetase syndrome and atypical PML. In addition, a negative result for the JC virus in the CSF in these patients does not rule out a diagnosis of PML.

The authors state that they have no Conflict of Interest (COI).

\section{References}

1. Vandenbroucke E, Grutters JC, Altenburg J, Boersma WG,
Borg ter EJ, van den Bosch JMM. Rituximab in life threatening antisynthetase syndrome. Rheumatol Int 29: 1499-1502, 2009.

2. Noss EH, Hausner-Sypek DL, Weinblatt ME. Rituximab as therapy for refractory polymyositis and dermatomyositis. J Rheumatol 33: 1021-1026, 2006.

3. Lambotte O, Kotb R, Maigne G, Blanc F-X, Goujard C, Delfraissy JF. Efficacy of rituximab in refractory polymyositis. J Rheumatol 32: 1369-1370, 2005.

4. Levine TD. Rituximab in the treatment of dermatomyositis: an open-label pilot study. Arthritis Rheum 52: 601-607, 2005.

5. Gottenberg J-E, Guillevin L, Lambotte $\mathrm{O}$, et al. Tolerance and short term efficacy of rituximab in 43 patients with systemic autoimmune diseases. Ann Rheum Dis 64: 913-920, 2005.

6. Brulhart L, Waldburger J-M, Gabay C. Rituximab in the treatment of antisynthetase syndrome. Ann Rheum Dis 65: 974-975, 2006.

7. Kelesidis T, Daikos G, Boumpas D, Tsiodras S. Does rituximab increase the incidence of infectious complications? A narrative review. Int J Infect Dis 15: e2-e16, 2011.

8. Marie I, Ménard J-F, Hachulla E, et al. Infectious complications in polymyositis and dermatomyositis: a series of 279 patients. Semin Arthritis Rheum 41: 48-60, 2011.

9. Terrier B, Amoura Z, Ravaud P, et al. Safety and efficacy of rituximab in systemic lupus erythematosus: results from 136 patients from the French AutoImmunity and Rituximab registry. Arthritis Rheum 62: 2458-2466, 2010.

10. Manfro RC, Vedolin L, Cantarelli M, Oppitz P, Antunes ACM, Rieder CRM. Progressive multifocal leukoencephalopathy in a kidney transplant recipient after conversion to mycophenolic acid therapy. Transpl Infect Dis 11: 189-190, 2009.

11. Lindå $\mathrm{H}$, Heijne von $\mathrm{A}$, Major EO, et al. Progressive multifocal leukoencephalopathy after natalizumab monotherapy. N Engl J Med 361: 1081-1087, 2009.

12. Tan CS, Koralnik IJ. Progressive multifocal leukoencephalopathy and other disorders caused by JC virus: clinical features and pathogenesis. Lancet Neurol 9: 425-437, 2010.

13. Giraud G, Ramqvist T, Pastrana DV, et al. DNA from KI, WU and Merkel cell polyomaviruses is not detected in childhood central nervous system tumours or neuroblastomas. PloS one 4: e8239, 2009.

14. Barzon L, Squarzon L, Militello V, et al. WU and KI polyomaviruses in the brains of HIV-positive patients with and without progressive multifocal leukoencephalopathy. J Infect Dis 200: 17551758, 2009.

15. Barzon L, Squarzon L, Pacenti M, Scotton PG, Palù G. Detection of WU polyomavirus in cerebrospinal fluid specimen from a patient with AIDS and suspected progressive multifocal leukoencephalopathy. J Infect Dis 200: 314-315, 2009.

16. Lopes da Silva R. Polyoma BK virus: an emerging opportunistic infectious agent of the human central nervous system. Braz J Infect Dis 15: 276-284, 2011.

17. Weissert R. Progressive multifocal leukoencephalopathy. J Neuroimmunol 231: 73-77, 2011.

18. Tan CS, Dezube BJ, Bhargava P, et al. Detection of JC virus DNA and proteins in the bone marrow of HIV-positive and HIVnegative patients: implications for viral latency and neurotropic transformation. J Infect Dis 199: 881-888, 2009.

19. Amend KL, Turnbull B, Foskett N, Napalkov P, Kurth T, Seeger J. Incidence of progressive multifocal leukoencephalopathy in patients without HIV. Neurology 75: 1326-1332, 2010.

20. Molloy ES, Calabrese LH. Progressive multifocal leukoencephalopathy: a national estimate of frequency in systemic lupus erythematosus and other rheumatic diseases. Arthritis Rheum 60: 37613765, 2009.

21. Koralnik IJ, Boden D, Mai VX, Lord CI, Letvin NL. JC virus DNA load in patients with and without progressive multifocal leukoencephalopathy. Neurology 52: 253-260, 1999. 
22. Shah R, Bag AK, Chapman PR, Curé JK. Imaging manifestations of progressive multifocal leukoencephalopathy. Clin Radiol 65 : 431-439, 2010.

23. Falcó V, Olmo M, del Saz SV, et al. Influence of HAART on the clinical course of HIV-1-infected patients with progressive multifocal leukoencephalopathy: results of an observational multicenter study. J Acquir Immune Defic Syndr 49: 26-31, 2008.

24. Marzocchetti A, Di Giambenedetto S, Cingolani A, Ammassari A, Cauda R, De Luca A. Reduced rate of diagnostic positive detection of JC virus DNA in cerebrospinal fluid in cases of suspected progressive multifocal leukoencephalopathy in the era of potent antiretroviral therapy. J Clin Microbiol 43: 4175-4177, 2005.

25. Viallard JF, Lazaro E, Ellie E, et al. Improvement of progressive multifocal leukoencephalopathy after cidofovir therapy in a patient with a destructive polyarthritis. Infection 35: 33-36, 2007.

26. Carson KR, Evens AM, Richey EA, et al. Progressive multifocal leukoencephalopathy after rituximab therapy in HIV-negative patients: a report of 57 cases from the Research on Adverse Drug Events and Reports project. Blood 113: 4834-4840, 2009.

(C) 2015 The Japanese Society of Internal Medicine http://www.naika.or.jp/imonline/index.html 